\title{
Антоцианы плодов винограда: идентификация в условияХ градиентной ВЭЖХ и разделение методом флэш-хроматографии
}

\author{
Макаревич С.Л. ${ }^{1}$, Дейнека В.И. ${ }^{2}$, Чулков А.Н. ${ }^{3}$, \\ Дейнека Л.А. ${ }^{2}$, Селеменев В.Ф. ${ }^{4}$ \\ ${ }^{I}$ ФБОУ «Белгородская межобластная ветеринарная лаборатория», Белгород \\ ${ }^{2}$ ФГАОУ «Белгородский государственный нацииональный исследовательский университет», Белгород \\ ${ }^{3}$ ФГБОУ Белгородский филиал «Центр оченки качества зерна и продуктов его переработки», \\ Белгород \\ ${ }^{4}$ ФГБОУ ВО «Воронежский государственный университет», Воронеж
}

Поступила в редакцию 4.05.2017 г.

В работе методом обращенно-фазовой ВЭЖХ с диодно-матричным и массспектроскопическим детектированиями исследован состав антоцианового комплекса плодов популярного местного сорта винограда неизвестной селекции. По появлению производных 3,5диглюкозидов установлен гибридный характер данного сорта винограда. Показано, что вследствие сольватохромного эффекта количественная оценка видового состава по площадям пиков осложнена, однако при сопоставлении спектров, записанных при различном содержании в подвижной фазе ацетонитрила, найдена особая точка, при которой величина поглощения при СФ-детектировании не зависит от состава растворителя. Для выполнения анализа антоцианов винограда в изократических условиях предложен вариант флэш-хроматографии, позволяющий отделить неацилированные компоненты от ацилированных с использованием насадочных картриджей для твердофазной экстракции.

Ключевые слова: обращенно-фазовая ВЭЖХ, флеш-хроматография, виноград, 3,5-диглюкозиды, 3-глюкозиды, спектрофотометрическое детектирование

\section{Anthocyanins of grape fruits: the determination of types by gradient RP HPLC and the separation into two parts by flash chromatography}

\author{
Makarevitch S.L. ${ }^{1}$, Deineka V.I. ${ }^{2}$, Chulkov A.N. ${ }^{3}$, \\ Deineka L.A. ${ }^{2}$, Selemenev V.F. ${ }^{4}$ \\ ${ }^{1}$ Belgorod interregional veterinary laboratory, Belgorod \\ ${ }^{2}$ Belgorod National Research University", Belgorod \\ ${ }^{3}$ DEPARTMENT of Belgorod branch of «Centre of evaluation of quality of grain and products of its \\ processing», Belgorod \\ ${ }^{4}$ Voronezh state University, Voronezh
}

In the paper the method of reversed-phase HPLC with diode-array and mass spectroscopic detection was used for investigated of the grape anthocyanin species composition of the popular local grape variety unknown breeding. The appearance of derivatives of 3,5-diglucosides indicates the hybrid nature of this grape variety. The anthocyanins specie composition has some specific fixture - the prevalence of delphinidine derivatives compared to that of petunidin and malvidin, as well as relatively high degree of acylation with acetic and $p$-coumaric acids. In this case only a gradient reversed-phase HPLC is an effective method for solute separation. But it has been shown that the solvatochromic effect impairs uncertainty to quantitative 
assessment of species composition by the areas of the peaks on the chromatogram. Though comparison of the grape anthocyanin spectra for various acetonitrile concentrations revealed a specific point on the spectra with absorption not dependent upon solvent composition. The wave length of the point was proposed to register the chromatogram for quantitative calculation of anthocyanins species composition. To make it possible to perform the anthocyanins separation by isocratic HPLC the flash chromatography was used to separate anthocyanin components into two parts, non-acylated and acylated compounds by the usage of syringe cartridges for the solid phase extraction.

Keywords: RP-HPLC, flash chromatography, grapes, 3,5-diglucoside, 3-glucosides spectrophotometric detection

\section{Введение}

Окраска от иссиня-черной до бледно-красной окрашенных сортов винограда (Vitis vinifera) определяется биосинтезом в их плодах уникальных соединений - антоцианов [1]. Антоцианы входят в обширный класс флавоноидов, выделяясь в нем хорошей растворимостью в воде и высокими антиоксидантными свойствами [2]. Поэтому не удивительно, что именно этим соединениям приписывается известный «французский парадокс», - заметное региональное снижение частоты заболевания сердечно-сосудистой системы вследствие регулярного умеренного употребления сухого красного вина [3]. Определение антоцианов необходимо как для оценки пищевой ценности винограда и производимой из него продукции, так и для контроля генетической чистоты $V$. vinifera. Дело в том, что при селекции более морозоустойчивых используют сорта винограда, происходящие из Северной Америки или Дальнего Востока, оставляющие свой след в виде биосинтеза 3,5 -диглюкозидов (3,5diG и их производных) пяти основных антоцианидинов: цианидина (Cy), пеонидина ( $\mathrm{Pn})$, дельфинидина (Dp), петунидина (Pt) и мальвидина (Mv) $[1,4]$. В генетически чистых сортах V. vinifera синтезируются только 3-глюкозиды (3G) этих агликонов, которые могут быть дополнены продуктами их ацилирования преимущественно уксусной и nара-кумаровой кислотами [1].

Для определения состава антоцианового комплекса широко используется обращенно-фазовая ВЭЖХ в кислых подвижных водно-ацетонитрильных фазах [5]. Подкисление фаз позволяет перевести антоцианы в окрашенную флавилиевую форму, - в таких условиях устраняется мешающее влияние сопутствующих экстрактивных веществ. Порядок элюирования 3-глюкозидов не зависит от состава подвижной фазы и марки стационарной фазы, позволяя легко разделять все пять 3-глюкозидов:

$$
\mathrm{t}_{\mathrm{R}}(\mathrm{Dp} 3 \mathrm{G})<\mathrm{t}_{\mathrm{R}}(\mathrm{Cy} 3 \mathrm{G})<\mathrm{t}_{\mathrm{R}}(\mathrm{Pt} 3 \mathrm{G})<\mathrm{t}_{\mathrm{R}}(\mathrm{Pn} 3 \mathrm{G})<\mathrm{t}_{\mathrm{R}}(\mathrm{Mv} 3 \mathrm{G}) .
$$

При появлении 3,5-диглюкозидов ситуация усложняется за счет уменьшения времени удерживания однотипных производных и зависимости его от состава подвижной фазы и от марки стационарной фазы. При этом оптимальным является использование элюентов с относительно небольшой концентрацией органического модификатора. При наличии в образце производных, ацилированных уксусной и napaкумаровой кислотами удерживание, напротив, резко возрастает. Поэтому единственная возможность мониторинга полного состава антоцианового комплекса - использование градиентного режима элюирования, при котором антоцианы элюируются в подвижных фазах различного состава. Возникающий при этом сольватохромный эффект затрудняет количественный анализ по величинам площадей пиков. Возможно этот эффект является одной из причин огромной разницы в результатах определения концентрации антоцианов в одних и тех же образцах двумя методами - спектрофотометрическим и хроматографическим [6].

Цель настоящей работы - разработка способа определения состава сложных смесей антоцианов в изократических условиях для широкого диапазона липофиль- 
ности компонентов сложной смеси с использованием метода их предварительного разделения с помощью флэш-хроматографии.

\section{Эксперимент}

В качестве объектов исследования использовали один из самых популярных морозоустойчивых и неприхотливых сортов неизвестного происхождения, широко выращиваемый на дачах и приусадебных участках Белгорода под названием «Изабелла». Особенность сорта состоит в его интенсивной окраске, поэтому даже отходы после отжима сока являются прекрасным вторичным сырьем для переработки с целью получения природного красителя. Отметим, что выполненный нами анализ антоцианов плодов этого винограда показал, что к настоящей «Изабелле» сорт отношения не имеет [7], поэтому он назван сортом X. Антоцианы из растительного материала экстрагировали водным $0.1 \mathrm{M}$ раствором соляной кислоты.

Перед хроматографированием экстракты были очищены от ряда сопутствующих экстрактивных веществ методом твердофазной экстракции на концентрирующих патронах ДИАПАК С18 (БиоХимМак СТ, Москва). Для этого экстракт отделяли от твердого остатка фильтрованием через бумажный фильтр. Затем сорбцию антоцианов из полученного экстракта проводили на насадочных картриджах (концентрирующих патронах) до проскока антоцианов.

При разработке способа разделения всех компонентом методом флэшхроматографии сорбированные на картридже антоцианы десорбировали последовательными порциями экстрагента с увеличением элюирующей силы, увеличивая концентрацию ацетонитрила от 3 до 30\% при постоянном содержании муравьиной кислоты - $10 \%$. Оптимальные условия такого разделения, выполненного при температуре в лаборатории $20^{\circ} \mathrm{C}$ :

1) насадочный картридж (патрон ДИАПАК С18) активировали, пропуская через него 5 мл ацетона;

2) картридж кондиционировали, пропуская 10-15 см 3 водного раствора $\mathrm{HCl}$;

3) сорбировали на картридж $1.0 \div 1.5$ мг антоцианов (в пересчете на мальвидин-3-глюкозид), пропуская экстракт плодов винограда в $0.1 \mathrm{M}$ водном растворе $\mathrm{HCl}$;

4) картридж промывали, пропуская $1 \mathrm{~cm}^{3} 0.1 \mathrm{M}$ водного раствора $\mathrm{HCl}$;

5) первую порцию элюата получали, пропуская через картридж элюент А, coдержащий 10 об.\% ацетонитрила и 10 об.\% муравьиной кислоты в дистиллированной воде, до значительного ослабления окраски элюата (до слабого розового цвета), для этого потребуется не более $7 \mathrm{~cm}^{3}$ элюента А;

6) остальные антоцианы экстрагировали с картриджа, пропуская элюент Б, содержащий 30 об.\% ацетонитрила и 30 об.\% муравьиной кислоты в дистиллированной воде (до обесцвечивания или до слабой розовой окраски элюата в зависимости от числа галерейных пор в сорбенте [11]), для этого потребуется не более $2 \mathrm{~cm}^{3}$ элюата Б. Элюат Б разбавляли водой в соотношении $1: 2$ перед ВЭЖХ анализом.

В работе использован хроматограф фирмы Agilent 1260 с диодно-матричным и масс-спектрометрическим детекторами. В качестве элюентов использовали водноацетонитрильные смеси, подкисленные муравьиной кислотой $(10 \%)$ в изократическом / градиентном режимах. Разделение компонентов проводили на хроматографической колонке 4.6×250 мм, Symmetry®C18, 5 мкм (при спектрофотометрическом детектировании) и $2.1 \times 150$ мм, Kromasil 100-5C18 (при масс-спектрометрическом детектировании); температура термостата колонок $40^{\circ} \mathrm{C}$.

Для градиентного элюирования использовали элюент А $8 \%$ ацетонитрила и $10 \%$ муравьиной кислоты в воде и элюент Б состава $16 \%$ ацетонитрила и $10 \%$ му- 
равьиной кислоты в воде. Режим: 0 мин - 0\% Б, до 20 мин $-100 \%$ Б, 30 мин $-100 \%$ Б, 31 мин - 0\% Б с изократической выдержкой в течение 10 мин. Липофильность по шкале miLogP рассчитывали интерактивно на сайте Molinspiration, http://www.molinspiration.com/.

\section{Обсуждение результатов}

Применение органических растворителей при спектрофотометрическом определении [8] и градиентное элюирование затрудняют количественное определение антоцианов из-за наличия сольватохромного эффекта, приводящего к изменению положения и интенсивности полос поглощения веществ на электронных спектрах [9]. Для его оценки одинаковые объемы экстракта плодов винограда X в 0.1 М водном растворе $\mathrm{HCl}$ смешивали с заданным количеством ацетонитрила и доводили объем до метки водой. Оказалось, что при увеличении содержания ацетонитрила (от 0 до 25\%) наблюдается батохромный сдвиг максимума поглощения на 10 нм, дополненный гиперхромным эффектом (рис.1).

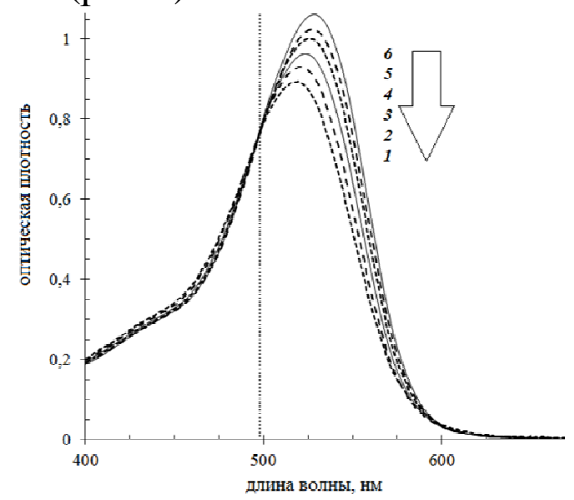

Рис. 1. Влияние добавок ацетонитрила на спектральные характеристики экстракта плодов винограда X

Доля ацетонитрила: 1 - 0, 2-5, $3-10,4-15,5-20$ и $6-25$ об. \%.

При длине волны 495 нм величина поглощения почти не зависит от состава растворителя, поэтому данную длину волны можно рекомендовать к использованию при записи хроматограмм в градиентном режиме для прямого расчета содержания индивидуальных антоцианов по площадям пиков. Хроматограмма экстракта плодов винограда сорта $\mathrm{X}$, записанная в условиях градиентного элюирования, представлена на рис.2. Отнесение пиков на ней выполнено по масс-спектрам и по электронным спектрам (табл. 1).

По полученным данным сорт X относится к дельфинидиновому типу [10], отличаясь от обычных сортов неожиданно высоким содержанием производных дельфинидина, а не мальвидина. При этом содержание 3,5-диглюкозидов в гибридных сортах относительно небольшое: на хроматограмме видны незначительные пики 3,5диглюкозидов дельфинидина, цианидина, петунидина и пеонидина $(0.2,0.4,0.7$ и $0.4 \%$, соответственно). Пик аналогичного производного мальвидина соэлюируется с пиком петунидин-3-глюкозида в условиях записи хроматограмм. Специфика антоцианового комплекса такова, что продукты ацилирования 3,5-диглюкозидов napaкумаровой кислотой также обнаруживаются на хроматограмме, давая в сумме около $7 \%$ от суммы площадей пиков. Это указывает на гибридный характер винограда сорта $\mathrm{X}$, полученного с участием морозостойких видов винограда. Пики 3.5диглюкозидов, как и их ацилированные производные, могут быть распознаны не только по электронным и масс-спектрам, но и по характерному заметно большему 
уширению пиков по сравнению с компонентами антоциановых комплексов плодов виноградов вида $V$. vinifera. Производные 3,5-диглюкозидов, ацилированнные уксусной кислотой, на хроматограмме не обнаружены. По вкладу в суммарный антоциановый комплекс 3-глюкозидов пяти агликонов, ацилированных уксусной (в сумме $12.8 \%)$ и пара-кумаровой кислотами $(20.8 \%)$ виноград сорта Х относится к наиболее ацилированным из всех сортов винограда, которые были исследованы в нашей лаборатории.

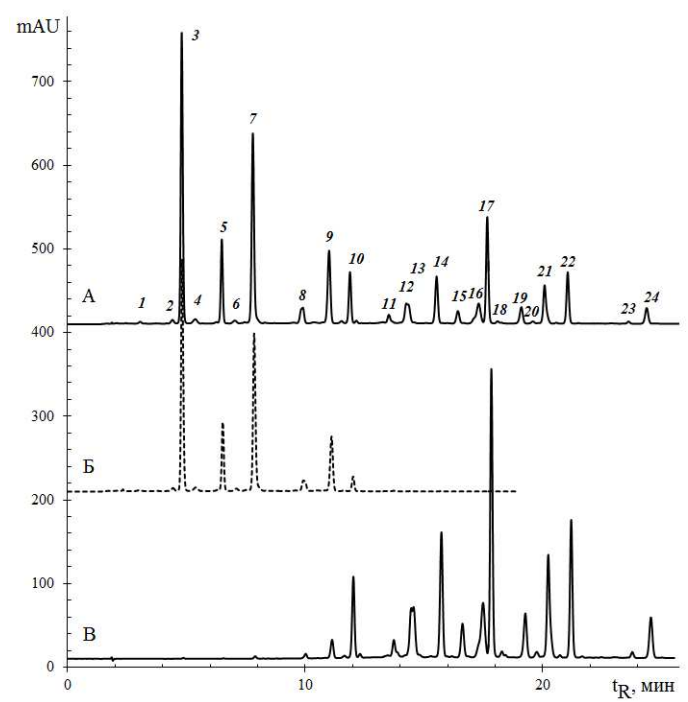

Рис. 2. Разделение всего комплекса антоцианов плодов винограда сорта X (A) в условиях градиентного элюирования и продуктов разделения экстракта на две части (Б и В) методом флэш-хроматографии

Таблица 1. Параметры веществ, разделенных на хроматограмме на рис. 2

\begin{tabular}{|c|c|c|c|c|}
\hline № & Антоциан & $\begin{array}{c}\mathrm{t}_{\mathrm{R}}, \\
\mathrm{Muн}\end{array}$ & $\begin{array}{c}\lambda_{\max }, \\
\mathrm{HM}\end{array}$ & $\mathrm{m} / \mathrm{z}$ \\
\hline 1 & 2 & 3 & 4 & 5 \\
\hline 1 & дельфинидин-3,5-диглюкозид & 3.06 & 523 & $-*$ \\
\hline 2 & цианидин-3,5-диглюкозид & 4.42 & 515 & - \\
\hline 3 & дельфинидин-3-глюкозид & 4.81 & 524 & $465.2 ; 303.1$ \\
\hline 4 & петунидин-3,5-диглюкозид & 5.37 & 524 & - \\
\hline 6 & цианидин-3-глюкозид & 6.49 & 516 & $449.2 ; 287.1$ \\
\hline 7 & пеоннидин-3,5-диглюкозид & 7.04 & 516 & - \\
\hline 8 & петунидин-3-глюкозид & 7.80 & 525 & $479.2 ; 317.1$ \\
\hline 9 & пеонидин-3-глюкозид & 9.80 & 516 & $463.2 ; 301.1$ \\
\hline 10 & мальвидин-3-глюкозид & 11.01 & 526 & $493.2 ; 331.1$ \\
\hline 11 & дельфинидин-3-(ацетилглюкозид) & 11.89 & 525 & $507.2 ; 303.1$ \\
\hline 12 & не определен & 13.53 & & - \\
\hline 13 & дельфинидин-3-(пара-кумароилглюкозид)-5- & 14.26 & 531 & $773.3 ; 611.2 ;$ \\
\hline 14 & глюкозид & 14.35 & 514 & $491.2 ; 287.1$ \\
\hline 15 & цианидин-3-(ацетилглюкозид) & 15.53 & 527 & $521.2 ; 317.1$ \\
\hline 16 & петунидин-3-(ацетилглюкозид) & 16.43 & 520 & $757.2 ; 595.2 ;$ \\
\hline 17 & пианидин-3-(пара-кумароилглюкозид)-5-глюкозид & 287.1 \\
\hline 18 & дельфинидин-3-(пара-кумароилглюкозид) & 17.66 & 529 & $611.2 ; 303.1$ \\
\hline 19 & пеонидин-3-(ацетилглюкозид) & 18.10 & 517 & - \\
\hline & мальвидин-3-(ацетилглюкозид) & 19.10 & 529 & $535.2 ; 331.1$ \\
\hline
\end{tabular}




\begin{tabular}{|c|c|c|c|c|}
\hline 1 & 2 & 3 & 4 & 5 \\
\hline 20 & производное цианидина & 19.58 & 525 & - \\
\hline \multirow{2}{*}{21} & цианидин-3-(пара-кумароилглюкозид) & & 525 & $595.2 ; 287.1$ \\
\cline { 5 - 6 } & мальвидин-3-(пара-кумароилглюкозид)-5- & 20.08 & 531 & $\begin{array}{c}801.3 ; 639.2 ; \\
\text { глюкозид }\end{array}$ \\
\cline { 5 - 6 } & петунидин-3-(пара-кумароилглюкозид) & 21.05 & 531 & $625.2 ; 317.1$ \\
\hline 22 & пеонидин-3-(пара-кумароилглюкозид) & 23.61 & 522 & - \\
\hline 24 & мальвидин-3-(пара-кумароилглюкозид) & 24.37 & 532 & $639.2 ; 331.2$ \\
\hline
\end{tabular}

Затруднительной остается оценка соотношения количества антоцианов, поскольку при записи хроматограммы в градиентном режиме последовательные пики элюируются в различных составах подвижной фазы, т.е. при неконтролируемом сольватохромном эффекте. Более того, каждый из пиков имеет различный состав подвижной фазы на фронте и на тыльной части. Ограниченная доступность стандартных образцов антоцианов делает невозможным их определение методом добавок и градуировочного графика. Учитывая найденную ранее точку на электронном спектре (рис. 1), подобную изобестической, можно предложить в качестве первого варианта использовать площади пиков, записанные при $\lambda=495$ нм (табл.2).

Таблица 2. Относительные доли антоцианов по площадям пиков, записанным при различных длинах волн детектора

\begin{tabular}{|c|c|c|c|c|c|}
\hline \multirow{2}{*}{ №* } & \multirow{2}{*}{ Антоциан } & \multirow{2}{*}{$t_{R}$, мин. } & \multicolumn{3}{|c|}{$\lambda$ детектирования, нм } \\
\hline & & & 495 & 524 & 532 \\
\hline 1 & дельфинидин-3,5-диглюкозид & 3.06 & 0.2 & 0.2 & 0.2 \\
\hline 2 & цианидин-3,5-диглюкозид & 4.42 & 0.5 & 0.4 & 0.3 \\
\hline 3 & дельфинидин-3-глюкозид & 4.81 & 24.6 & 23.1 & 22.9 \\
\hline 4 & петунидин-3,5-диглюкозид & 5.37 & 0.7 & 0.7 & 0.7 \\
\hline 5 & цианидин-3-глюкозид & 6.49 & 7.5 & 6 & 5.5 \\
\hline 6 & пеоннидин-3,5-диглюкозид & 7.04 & 0.4 & 0.3 & 0.3 \\
\hline 7 & петунидин-3-глюкозид & 7.8 & 18.2 & 18.3 & 18.4 \\
\hline 8 & пеонидин-3-глюкозид & 9.8 & 1.8 & 1.6 & 1.5 \\
\hline 9 & мальвидин-3-глюкозид & 11.01 & 7.9 & 8.1 & 8.3 \\
\hline 10 & дельфинидин-3-(ацетилглюкозид) & 11.89 & 4.2 & 4.3 & 4.3 \\
\hline 11 & не определен & 13.53 & 0.3 & 0.1 & 0.1 \\
\hline 12 & $\begin{array}{c}\text { дельфинидин-3-(napa-кумароилглюкозид)-5- } \\
\text { глюкозид }\end{array}$ & 14.26 & 2.6 & 2.4 & 0.5 \\
\hline 13 & цианидин-3-(ацетилглюкозид) & 14.35 & 1.3 & 1.3 & 1.8 \\
\hline 14 & петунидин-3-(ацетилглюкозид) & 15.53 & 4.6 & 4.8 & 4.9 \\
\hline 15 & цианидин-3-(nара-кумароилглюкозид)-5-глюкозид & 16.43 & 1.4 & 1.3 & 1.2 \\
\hline 16 & петунидин-3-(napa-кумароилглюкозид)-5-глюкозид & 17.3 & 2.5 & 2.9 & 3.1 \\
\hline 17 & дельфинидин-3-(nара-кумароилглюкозид) & 17.66 & 8.8 & 9.4 & 9.8 \\
\hline 18 & пеонидин-3-(ацетилглюкозид) & 18.1 & 0.2 & 0.2 & 0.1 \\
\hline 19 & мальвидин-3-(ацетилглюкозид) & 19.1 & 1.8 & 2 & 2 \\
\hline 20 & производное цианидина & 19.58 & 0.2 & 0.2 & 0.2 \\
\hline \multirow{2}{*}{21} & цианидин-3-(napa-кумароилглюкозид) & \multirow{2}{*}{20.08} & \multirow{2}{*}{4.2} & \multirow{2}{*}{4.3} & \multirow{2}{*}{4.3} \\
\hline & мальвидин-3-(nара-кумароилглюкозид)-5-глюкозид & & & & \\
\hline 22 & петунидин-3-(nара-кумароилглюкозид) & 21.05 & 4.6 & 5 & 5.2 \\
\hline 23 & пеонидин-3-(nара-кумароилглюкозид) & 23.61 & 0.2 & 0.2 & 0.2 \\
\hline 24 & мальвидин-3-(napa-кумароилглюкозид) & 24.37 & 1.8 & 1.9 & 2 \\
\hline \multicolumn{3}{|c|}{ Относительная суммарная площадь пиков } & 1.00 & 1.36 & 1.33 \\
\hline
\end{tabular}


При использовании предложенной аналитической длины волны пиков доли индивидуальных антоцианов, рассчитанные по площадям в сложной смеси, отличаются от долей, рассчитанных при записи хроматограммы при 524 нм (длине волны, соответствующей максимуму абсорбции дельфинидин-3-глюкозида) или - при 532 нм (соответствующей максимуму абсорбции последнего пика, мальвидин-3-(napaкумароилглюкозида)). Так, например, доля дельфинидин-3-глюкозида оказывается заметно большей, а доля дельфинидин-3-(nара-кумароилглюкозида) - оказывается заметно меньшей, чем при альтернативных вариантах записи хроматограмм, не учитывающих сольватохромные эффекты.

Другим решением проблемы является запись хроматограммы в изократическом режиме. Однако присутствие в смеси компонентов с существенно различающейся липофильностью осложняет работу в относительно «медленных» элюентах, позволяющих разделить первые пики, из-за необходимости удаления с колонки прочно сорбировавшихся веществ после каждого ввода пробы для исключения последующего наложения пиков из различных партий пробы. Особенно это имеет значение при полупрепаративном разделении антоцианов в изократических условиях. Именно такой, широкий по диапазону липофильности (в единицах miLogP), набор антоцианов может быть обнаружен в плодах винограда: от -4.76 для дельфинидина3,5-диглюкозида до -0.01 для мальвидина-3-(nара-кумароилглюкозида).

Bсе выше приведенные хроматограммы записаны в условиях градиентного элюирования. Для упрощения разделения антоцианов всего комплекса мы исследовали возможность разделения антоцианов по липофильности во время обязательной перед ВЭЖХ процедуры - твердофазной очистки, используя технику флэшхроматографии. Оказалось, что весь антоциановый комплекс плодов винограда сорта $\mathrm{X}$ может быть разделен на две части: в первой из них находятся все пять неацилированных 3-глюкозидов с примесью наиболее слабо удерживающегося дельфинидин3-(ацетилглюкозида). Во второй части остаются все ацилированные антоцианы с небольшой примесью 3-глюкозида мальвидина, рис.2.

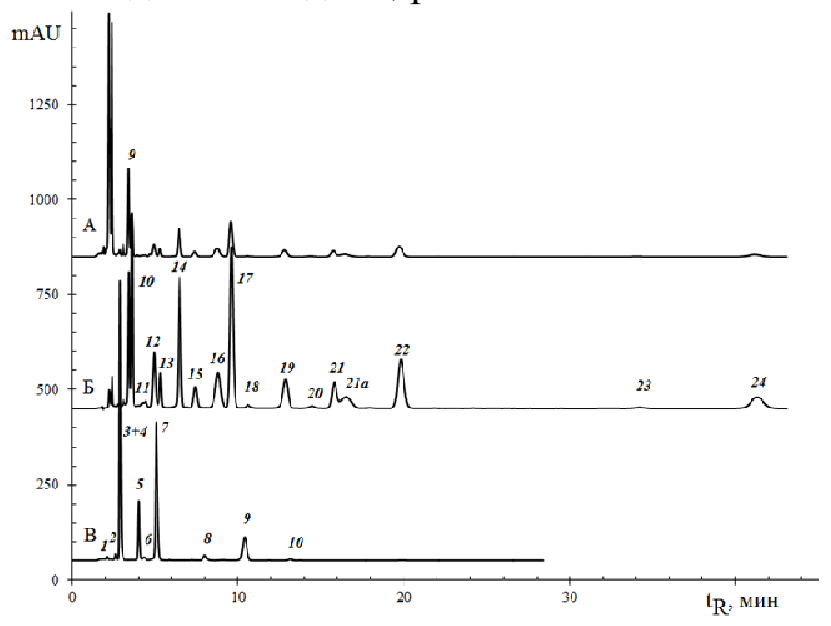

Рис. 3. Разделение антоцианов двух частей экстракта плодов винограда сорта X (А) в условиях изократического элюирования

А - исходный экстракт; Б - ацилированные антоцианы в элюенте состава: 10 об.\% муравьиной кислоты и 10 об.\% ацетонитрила в воде, $0.8 \mathrm{~cm}^{3} /$ мин; В - неацилированные антоцианы в элюенте состава: 10 об.\% муравьиной кислоты и 10 об.\% ацетонитрила в воде, $0.8 \mathrm{~cm}^{3} /$ мин. Температура термостата колонок $40^{\circ} \mathrm{C}$. Хроматограммы записаны при 495 нм.

При использовании предварительного разделения антоцианов на две группы можно воспользоваться двумя различными составами подвижной фазы при одинаковой концентрации муравьиной кислоты (10\%) в смесях с водой: 
I - 10\% ацетонитрила, - для разделения неацилированных антоцианов, рис.3В, и II - 14\% ацетонитрила, - для разделения ацилированных антоцианов, рис.3А.

Отметим, что в изократических условиях разделились два пика под номером 21, среди которых пик мальвидин-3-(nара-кумароилглюкозид)-5-глюкозида легко обнаруживается по относительно большей ширине (21a).

\section{Заключение}

Таким образом, популярный морозоустойчивый и неприхотливый местный сорт винограда неизвестной селекции содержит производные 3,5-диглюкозидов, что указывает на его гибридный характер. Он отличается также низкой степенью метилирования (т.е. повышенной долей производных дельфинидина и петунидина) и относительно высокой степенью ацилирования антоцианов уксусной и пара-кумаровой кислотами. Для определения соотношения долей видов антоцианов при градиентном элюировании предложено использование длины волны (495 нм), нивелирующей сольфатохромные эффекты. Использование насадочных картриджей для твердофазной экстракции позволяет разделить весь антоциановый комплекс на две части для последующего определения антоцианов с использованием изократической обращенно-фазовой ВЭЖХ.

\section{Список литературы}

1. He F., Mu L., Yan G.-L., Liang N.-Na. et al. // Molecules. 2010. Vol. 15, pp. 9057-9091.

2. Prior R.L., Wu X. // Free Radical Res. 2006. Vol. 40. pp. 1014-1028.

3. Ferrières J. // Heart. 2004. Vol. 90. pp. 107111.

4. Flamini R., Tomasi D. // Vitis. 2000. Vol. 39. pp. 79-81.

5. Berente B., Reichenbächer M., Danzer K. // Fresenius J. Anal. Chem. 2001. Vol. 371. pp. 68-72.

6. Lee J., Rennaker C., Wrolstad R.E. // Food Chem. 2008. Vol. 110. pp. 782-786.

7. Макаревич С.Л., Чулков А.Н., Дейнека В.И., Костенко М.О. и др. // Сорбиионные и

\section{References}

1. He F., Mu L., Yan G.-L., Liang N.-Na et al., Molecules., 2010, Vol. 15, pp. 9057-9091. doi:10.3390/molecules15129057. Available at http://www.mdpi.com/1420-3049/15/12/9057

2. Prior R.L., Wu X., Free Radical Res., 2006 , Vol. 40, pp. 1014-1028. http://dx.doi.org/ $\underline{10.1080 / 10715760600758522}$

3. Ferrières J., Heart, 2004, Vol. 90, pp. 107111, $\quad$ https://www.ncbi.nlm.nih.gov/pmc /articles/PMC1768013/pdf/hrt09000107.pdf

4. Flamini R., Tomasi D., Vitis. 2000. Vol. 39, pp. 79-81, http://www.vitis-vea.de/admin/ volltext/e043505.pdf хроматографические проиессы. 2014. Т. 14. № 6. C. 1024-1031.

8. Giusti M.M., Wrolstad, R.E. / Current Protocols in Food Analytical Chemistry / Ed. Wrolstad R.E., New York, NY: John Wiley \& Sons, 2001. UNIT F1.2.

9. Reichardt C. // Chem. Rev. 1994. Vol. 94. pp. 2319-2358.

10. Дейнека Л.А., Литвин Ю.Ю., Дейнека В.И. // Научные ведомости БелГУ. Серия: Естественные науки. 2008. №7(47). Вып. 7. C. 71-78.

11. Дейнека В.И., Дейнека Л.А., Сидоров А.Н., Саенко И.И.и др. // Сорбиионные и хроматографические прочессы. 2016. Т. 16. № 5. C. 624-630.

5. Berente B., Reichenbächer M., Danzer K., Fresenius J. Anal. Chem., 2001, Vol. 371, pp. 68-72, Available at https://link.springer. com/article/10.1007/s002160100940

6. Lee J., Rennaker C., Wrolstad R.E., Food Chem., 2008, Vol. 110, pp. 782-786. http://doi.org/10.1016/j.foodchem.2008.03.010

Available at: http://www.sciencedirect.com/ science/article/pii/S030881460800304X

7. Makarevitch S.L., Chulkov A.N., Deineka V.I., Kostenko M.O. et al., Sorbtsionnye $i$ khromatograficheskie protsessy, 2014, Vol. 14, No 6, pp. 1024-1031. 
8. Giusti M.M., Wrolstad, R.E. / Current Protocols in Food Analytical Chemistry / Ed. Wrolstad R.E., New York, NY: John Wiley \& Sons, $2001 . \quad$ UNIT F1.2. DOI: 10.1002/0471142913.faf0102s00. Available at: http://onlinelibrary.wiley.com/ doi/10.1002/0471142913.faf0102s00/abstract

9. Reichardt C., Chem. Rev., 1994, Vol. 94, pp. 2319-2358. DOI: $10.1021 /$ cr00032a005.

Макаревич Сергей Леонидович - инженерхимик, Белгородская межобластная ветеринарная лаборатория, Белгород

Дейнека Виктор Иванович - профессор кафедры общей химии, д.х.н., Белгородский государственный национальный исследовательский университет, Белгород

Чулков Андрей Николаевич - к.т.Н., Белгородский филиал «Центр оценки качества зерна и продуктов его переработки», Белгород

Дейнека Людмила Александровна - доцент кафедры общей химии, к.х.н., Белгородский государственный национальный исследовательский университет, Белгород

Селеменев Владимир Федорович - д.Х.Н., проф., зав. каф. аналитической химии химического факультета Воронежского государственного университета, Воронеж
Available at: http://pubs.acs.org/doi/abs 110.1021/cr00032a005

10. Deineka L.A., Livin Yu.Yu., Deineka V.I., Nauchnye vedomosti BelGU. Seriya: Estestvennye nauki, 2008, Vol. 7(47), No 7, pp. 71-78.

11. Deineka V.I., Deineka L.A., Sidorov A.N., Saenko I.I. et al., Sorbtsionnye i khromatograficheskie protsessy, 2016, Vol. 16, No 5, pp. 624630.

Макаrevitch Sergey L. - chemical engineer, Belgorod Interregional Veterinary laboratory, Belgorod, e-mail: sergmazay@yandex.ru

Deineka Victor I. - Dr. Sci. (Chemistry), professor of Common Chemistry Chair of Institute of Engineering Technologies and Natural Sciences of Belgorod State National Research University, Belgorod, e-mail: deineka@bsu.edu.ru

Chulkov Andrey N. - Ph.D., Belgorod Branch of Federal State-Funded Institution «Federal Centre of Quality and Safety Assurance for Grain and Grain products», Belgorod, E-mail: Ach87@mail.ru

Deineka Ludmila A. - Ph.D. (Chemistry), professor assistant of Common Chemistry Chair of Institute of Engineering Technologies and Natural Sciences of Belgorod State National Research University, Belgorod

Selemenev Vladimir F. - the professor, head of the department of Analitical chemistry, Voronezh State University, Voronezh 